April - 2004

\title{
Distance Learning for Teacher Training in Brazil
}

\author{
Alvana Maria Bof \\ Brazilian Ministry of Education
}

\begin{abstract}
Proformação is a distance teacher certification course aimed at providing training to 27,000 uncertified teachers in 15 Brazilian states. This innovative program organizes human and technical resources for delivering distance education in a cost-effective manner. Different from other institutional systems - which typically employ their own dedicated content, design, and instructional resource personnel, and accompanied by a large pool of administrative staff Proformação leverages pre-existing learning resources such as content experts, technology specialists, instruction, and student support systems from several institutions. Proformação goal is to create a viable teacher certification course to upgrade thousands of non-certified teachers working in the field. Proformação is coordinated by an administrative unit of the Brazilian Ministry of Education. To support the program, an information system was implemented to continuously and consistently monitor the program's activities and results. Results of an external evaluation have been positive; Proformação is regarded by some as an innovative model for delivering decentralized training opportunities to large student numbers. Therefore, the findings in this article may prove interesting to those charged with implementing distance learning initiatives in developing countries, in that the lessons learned in Brazil may help others interested in implementing similar distance training programs.
\end{abstract}

Keywords: distance teacher training; distance education; in-service teacher training; distance education in developing countries

\section{Introduction}

Distance learning is a viable avenue for developing countries to provide education opportunities to their population. In contrast to developed countries, however, which typically can afford comprehensive distance learning systems (e.g., full service open and distance universities) developing countries usually lack the resources and funding for such costly endeavors. This means developing countries must often seek innovative lower cost strategies for the delivery of distance education programming.

This article describes a viable distance learning in-service training program developed to upgrade 27,000 teachers working throughout Brazil. The program described has proven to be a successful model for the delivery of education at a distance. While exhibiting all the important features of distance teaching institutions around the world, this model does so without the establishment of a traditional bricks-and-mortar institution. Instead, this model, which is coordinated by a management unit in the Brazilian Ministry of Education, is comprised of a collaborative, decentralized system that leverages human and technical resources from several institutions. 
Providing an innovative and cost-effective way of delivering training, Proformação is regarded by Moore (2001) as “a distance learning program for the 21 Century.” In sum, Proformação may be of particular interest to those seeking to implement distance education other developing countries.

This article describes the design and implementation structure of Proformação. It also reports the results of an external evaluation. The article concludes by summarizing the lessons learned during the implementation process.

\section{The Program}

Proformação is a distance teacher certification course aimed at upgrading those individuals teaching the first four primary school grades in the North, Northeast, and Midwest regions of Brazil. It employs a distance education model that combines self-study, school-based practice, local-based biweekly meetings for tutors and teacher-trainees, and a supportive communication network to provide assistance and support to tutors and teacher-trainees operating through Training Agencies, located in each Brazilian State.

\section{Objectives}

The main objectives of the Proformação are to:

- Certify un-certified teachers teaching literacy classes and the first four years of primary school

- Increase the knowledge base, abilities, and professional qualifications of those individuals already working as teachers

- Improve of primary grade-level student learning and performance in Brazil's State and Municipal public schools

- Elevate the importance teaching, by promoting the image of "professionalization" of the teaching discipline

- Improvement in the quality of learning in Brazil

\section{Course Design}

The program's aim is to deliver 3,200 hours of training, divided into four modules (semesters), each comprising 800 hours of individual and group activities. These modules encompass:

- A face-to-face session held at local Training Agencies, during which teacher-trainees are introduced to each module's content and activities. This session is typically conducted during teachers' vacation period

- Individual activities outlined in a study guides, along with workbook exercises on course content, and journal entries kept by teacher-trainees to record their observations, progress, problems, and experiences in the classroom 
- Tutor evaluation of the teaching practice in the teacher-trainees' own schools following the course studies

- Tutorial meetings conducted every other Saturday. These tutorial meetings focus on guiding and monitoring the teacher-trainees' work in progress, and include support materials such as videos related to each of the Study Guide units, and a forum for discussion and dialog to clarify any problems or questions the teacher-trainees may have

- Bimonthly tests on all content areas

- Activities to prepare for the bimonthly tests - i.e., activities organized by the Training Agencies for teacher-trainees prior to test-taking

The program also includes school projects and a foreign language, as well as a permanent learning support system. In total, this program includes:

- Tutorials: learning support provided by a local tutor, who in turn are guided by the Training Agencies

- Communication services: communication services among tutors, Training Agencies, State Management Teams and the National Coordination Unit. This includes free educational assistance provided by the Training Agencies via toll-free telephone, that allows teacher-trainees to contact area content tutors to clarify any doubts they may have, or obtain additional information

\section{Curriculum and Trainee Evaluation}

Proformação's curriculum is based on The National Curriculum Parameters (NCP), and is organized in six thematic areas: 1) Codes and Language; 2) Mathematics and Logic; 3) Science and Environment; 4) Identity, Society and Culture; 5) Educational Foundations; and 6) Theory and Praxis of Education. Curriculum objectives and content take into account the general guidelines of Brazil's secondary education system, as well as the specific requirements for teacher certification. The curricula's nucleus is comprised of an interdisciplinary core, including a field research project were teacher-trainees must examine aspects of their local experience. This research project may address specific themes of local interest such as regional culture, environmental issues, local history, etc.

Evaluation of teacher-trainees takes place continuously and is based on an analysis of several evaluation instruments: workbook assignments, bi-monthly tests on the six thematic areas, class plans, observation of actual classroom practices, written reports (i.e., journal), and field research projects.

To be approved, the teacher-trainee must achieve an overall performance level equal to, or greater than, 60 percent; and not less than 50 percent on any specific individual evaluation instrument or any of the six thematic areas. 


\section{Materials}

Course and instructional materials were developed by a nationally-based team of subject matter specialists and instructional designers. Learning materials include:

- 32 study guides in the subjects that comprise the self-study part of the course

- 32 videos per module, for each of unit

- 32 workbooks with assignments

Proformação also offers printed material containing all the necessary information about the course, including orientation on how to use the methodology, implementation strategies, Proformação's operational structure, responsibilities of individual partners, and the roles and functions of tutors and the Training Agencies. These materials include: a general guide, operational guide, tutor guide, tutor support texts, tutor training video, Training Agency support text, etc.

\section{Implementation Structure}

Proformação’s organizational structure operates at three levels:

Federal level: Brazil's Federal Government is responsible for defining the technical and pedagogical design, developing and producing instructional materials, defining the implementation strategy, coordinating the implementation process, providing training to participants and technical support to states, and monitoring and evaluating processes and results. There is a national unit at the Brazilian Ministry of Education.

State level. Brazil's individual states are responsible for establishing a state management coordination (SMC) team, based in the State Secretariat of Education in charge of managing the program at the state level. This team selects and designates staff, and provides the infrastructure for Proformação’s Training Agencies.

Municipal level. Municipalities are responsible for the payment of tutors' wages, providing transport for tutors for visits to teacher-trainees' schools, and transport, meals, and accommodation for both teacher-trainees and tutors during the face-to-face sessions of Proformação.

Contrary to what typically occurs where there is a formal physical institution responsible for providing training, Proformação has created a virtual structure, comprising several actors and local institutions responsible for specific activities involved in the Program's implementation. This organizational structure was established by a partnership between Brazil's Federal, State, and Municipal governments, who signed a formal agreement outlining each level of governments' area of control.

The support system comprises: locally-based tutors that support the teacher-trainees; Training Agencies; the State Management Unit; technical assistants that support and monitor the Training Agencies; and the National Coordination Unit required to support, monitor, and evaluate the various state teams. Figure 2 shows this structure: 
The Training Agency is comprised of a team of six specialist teachers, one from each of the curriculum content areas, who are in turn responsible for selecting, training, and monitoring the work of the tutors. These six specialist teachers are also responsible for planning and implementing face-to-face in-service training activities, and organizing and managing the learning support system (including answering a toll free telephone number) for both tutors and teacher-trainees. As well as being the pedagogical center of the program, the Training Agency also acts as a micro management unit where teacher-trainees' academic data is collected, collated, analyzed, and evaluated. A communication system was installed (i.e., email; interactive television programs; and teleconferencing) for the Training Agencies, State Management Units, and the National Coordination Unit, to monitor teacher-trainee performance and manage the administrative aspects Proformação.

Figure 1. Proformação Organizational Structure

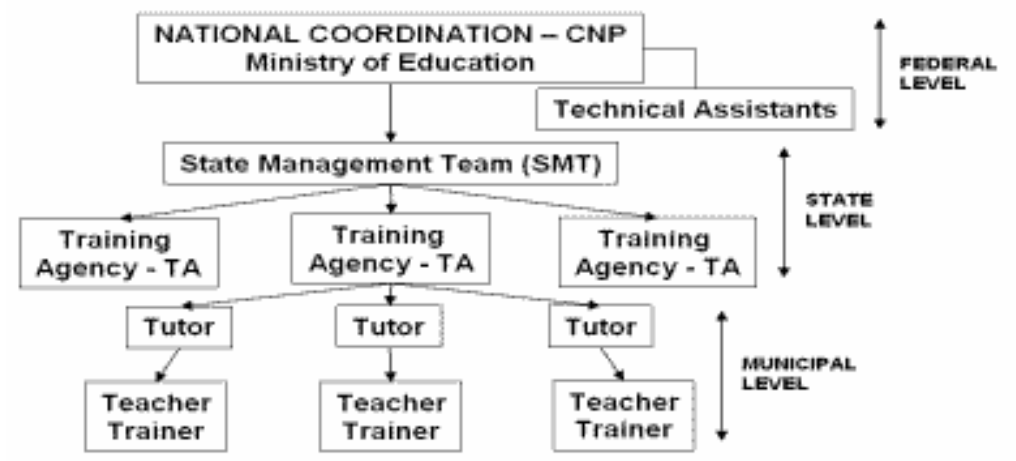

Tutors are selected among a pool of fully certified public school teachers. Those selected as tutors, receive training from their respective local Training Agencies, which serves as the "hub or base" from which they conduct biweekly meetings with local teacher-trainees, provide program orientation and training support, travel to visit the teacher-trainees' local school to guide and evaluate their pedagogical practice, and evaluate the their performance based on workbook assignments and journal entries. Each tutor typically supervises approximately 12 teachertrainees.

\section{Monitoring and Evaluation System}

Proformação installed a computer information system to collect and analyze data to track and assess teacher-trainee performance, and monitor the Program's processes, progress, and activities. Data collection at the Training Agency level allows the Training Agency team and the managers at state and national levels to track and evaluate Proformação's ongoing performance. Information is gathered in to evaluate teacher-trainees' performance by content area, region, or Training Agency, which in turn gives all participants involved the targeted level of information they need to resolve and/ or address problems as they arise.

Tutors and Training Agency staff continuously monitor teacher-trainees' performance at the local level. Tutors track and evaluate the teacher-trainees' work, enabling them to provide continuous feedback, and offer remedial help when and were needed, typically by offering additional exercises, explanations, etc. The Training Agencies also monitors teacher-trainee performance 
and addresses any difficulties, usually during monthly meetings with held with tutors. During these meetings, the group reviews the teacher-trainees' performance data (based on the six different thematic areas) using evaluative instruments designed to identify and assess difficulties. From these meetings, customized strategies are developed to improve the teacher-trainees' performance on a local and/or individual basis.

Program activities and student performance also monitored at the state and national levels. The National Coordination Unit employs technical assistants who work in each participating state. Their role is to visit the Training Agencies, to monitor their performance, observe biweekly meetings, conduct examinations and face-to-face sessions, etc. These professionals work with the State Management Team and submit standardized monthly reports to the National Coordination Unit. From these reports, the National Coordination Unit can take action to address any problems that arise at the state level.

Each semester, the National Coordination Unit also conducts systematic data review on all program implementation aspects by conducting face-to-face sessions with teacher-trainees, tutors, and teachers. Data results are discussed between the State Management Teams and their cadre of technical assessors, in order to identify problems and define strategies to resolve them.

The National Coordination Unit has also a support unit that establishes regular communication with the State Management Teams and the Training Agencies. Such communication and support take place via phone, email, an electronic bulletin, teleconferencing, as well as a printed bulletin, to convey news, information, and experiences from the Training Agencies and their tutors and teacher-trainees.

Proformação also holds midterm evaluation meetings and continuing education sessions for the staff of the Training, State, and National agencies. These meetings include presentations of performance data, information on new procedures, and follow-up discussions on these and other relevant topics. Recently, an interactive tele-conferencing system was implemented, allowing those working in the field at the Teaching Agencies, to work directly with the National Coordination Unit to define strategies. The tele-conference meetings are evaluated by all participants, the results of which help the National Coordination Unit improve the organization and content of future tele-conference meetings.

\section{Cost}

Proformação's cost per teacher-trainee is $\$ 1,100$ for the two-year course. The Ministry of Education covers 36 percent of the total cost. The remaining 64 percent of cost are shared among the State and Municipal governments.

\section{Results and External Evaluation}

Since the program's inception, a team of external evaluators from various Brazilian universities and institutions ${ }^{1}$ has been contracted to collect and analyze data. Their task is to identify issues concerning program implementation, and determine program results based on teacher-trainee performance, classroom practice, and the impact the program has had on the schools and in developing local communities. These findings inform any needed adjustments to the program. 
External evaluation comprises three main kinds of studies: (1) statistical analyses of trainee performance; (2) surveys of all participants; and (3) six case studies in different regions. The main findings are summarized below (Placco, 2002; André, 2002; Gatti, 2002).

\section{Teacher-Trainee Performance}

Performance data in Figure 1 shows that 85.7 percent of teacher trainees achieved certification/ promotion, 3 percent were retained; and 11.5 percent dropped out (Gatti, 2001). In contrast with the high dropout rates typically experienced in distance learning programs, these results are positive. In addition, when looking at performance in each of the content areas, results show that the majority of teacher-trainees perform well above of the minimum required for promotion.

Figure 2a. Teacher-Trainee Performance

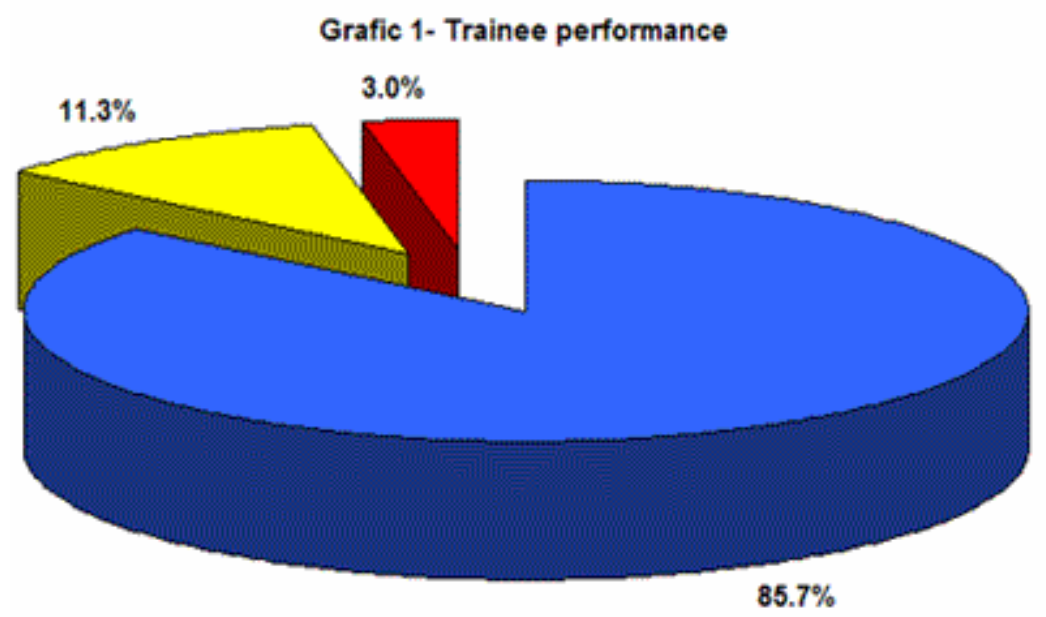

aPromotion aDropouts a Retention

Figure 2b. Teacher-Trainee Performance 


\begin{tabular}{|c|c|c|c|c|c|c|c|c|c|c|}
\hline \multirow[b]{2}{*}{ Grupo } & \multirow[b]{2}{*}{ Estados } & \multirow[b]{2}{*}{$\begin{array}{l}\text { Agêneias } \\
\text { Foermadoras }\end{array}$} & \multirow[b]{2}{*}{$\begin{array}{c}\text { Municipios } \\
\text { Adesidos }\end{array}$} & \multirow[b]{2}{*}{ ATP } & \multirow[b]{2}{*}{ PF } & \multirow[b]{2}{*}{ TR } & \multicolumn{4}{|c|}{ Cursistas } \\
\hline & & & & & & & Inseritos & $\begin{array}{c}\text { Promotio } \\
\text { n }\end{array}$ & Dropouts & Petention \\
\hline \multirow{2}{*}{ Pilote } & MT & 11 & 118 & 1 & 66 & 117 & 1,170 & 1.120 & & 0 \\
\hline & MS & 2 & 28 & 1 & 12 & 33 & 203 & 203 & & 0 \\
\hline \multicolumn{2}{|c|}{ SUBTOTAL } & 13 & 146 & 2 & 78 & 150 & 1,373 & 1,323 & 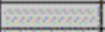 & 0 \\
\hline \multirow{8}{*}{ Ginpol 1} & $A C$ & 8 & 23 & 2 & 78 & 153 & 1,845 & 1.634 & 174 & 37 \\
\hline & $C E$ & 30 & 74 & 2 & 180 & 332 & 3.575 & 3013 & 419 & 143 \\
\hline & $\mathrm{GO}$ & 16 & 156 & 2 & 102 & 219 & 2,244 & 1.853 & 346 & 45 \\
\hline & $\mathrm{PB}$ & 17 & 102 & 1 & 108 & 149 & 1.537 & 1,358 & 148 & 31 \\
\hline & PE & 21 & 106 & 2 & 126 & 186 & 1.844 & 1.712 & 95 & 37 \\
\hline & PI & 19 & 76 & 2 & 120 & 240 & 2.414 & 2.179 & 163 & 72 \\
\hline & $\mathrm{RO}$ & 9 & 34 & 1 & 60 & 122 & 1.297 & 1.109 & 136 & 52 \\
\hline & $\overline{\mathrm{SE}}$ & 8 & 52 & 1 & 54 & 146 & 1,522 & 1,398 & 94 & 30 \\
\hline \multicolumn{2}{|c|}{ SUBTOTAL } & 128 & 623. & 13 & 828 & 1,547 & 16,278 & 14.256 & 1,575 & 447 \\
\hline \multirow{5}{*}{ Gropoll } & AL & 5 & 35 & 1 & 36 & 60 & 678 & 615 & 49 & 14 \\
\hline & $\overline{A M}$ & 6 & 25 & 2 & 42 & 131 & 1,274 & 1.003 & 195 & 76 \\
\hline & $B A$ & 30 & 174 & 2 & 186 & 422 & 4,435 & 3.627 & 631 & 177 \\
\hline & $\overline{\mathrm{MA}}$ & 12 & 50 & 1 & 78 & 207 & 2,431 & 1,935 & 423 & 73 \\
\hline & TO & 15 & 54 & 1 & 90 & 79 & 903 & 660 & 216 & 27 \\
\hline \multicolumn{2}{|c|}{ SUBTOTAL } & 68 & 338 & 7 & 432 & 899 & 9,721 & 7,840 & 1,514 & 367 \\
\hline \multirow[t]{2}{*}{ TOTAL } & & 209 & 1.107 & 22 & 1,338 & 2,596 & 27,372 & 23,419 & 3,088 & 815 \\
\hline & & & & & & & & $85.6 \%$ & $11.3 \%$ & 3.0 \\
\hline
\end{tabular}

This includes dropouts, teachers who were dismissed, and those who have died.

\section{Changes in Classroom Practice}

Results of a final survey conducted with about 2000 participants, showed that 99.4 percent of teacher-trainees felt that their teaching practices had improved after they joined Proformação. Ninety-seven percent of tutors and 99 percent of teacher-trainees also agreed this to be true. Changes in class planning, teaching methods, classroom management, and in teacher-trainees' attitudes towards their students, were also positively registered.

Nine-night percent of trainees agreed that their ability to plan classes has improved because of the program, and 98.8 percent believe that their classes are now more interesting for their students. Ninety-seven percent of teacher-trainees' surveyed reported that all students are capable of learning; 98.5 percent are allowing their students to participate more in class; and 83 percent reported that they are more sensitive and responsive to students' individual characteristics, differences, and needs.

These results are consistent with the results of case studies of this program, which revealed significant changes in the teacher-trainees' teaching practice in the classroom. Positive changes include: use of refined teaching strategies, methodology, and resources; use of games, reasoning activities, and concrete activities use to teach students; more emphasis placed on student participation; consideration of differing levels of student development; using student's previous knowledge in the educational setting; and overall positive changes in teacher-trainee's attitudes towards their students. "Besides creating a cozy learning environment, with several stimuli to learning, they develop diversified activities, promote student participation and keep the classroom with environment with mutual respect and trust” (André, 2002, pg. 19).

A field note entry by one researcher illustrates well the teacher-trainees' work in the classroom:

It is worthwhile to emphasize a math class observed on 06/11. According to the teacher, it was based on Proformação study guides. The class, divided into three groups of four students each (one was absent today), was to follow this plan: starting from some calculations showed by the teacher, each group should write 
math quizzes that would be exchanged among the groups. Each group would solve the quizzes from another group. The teacher asked them to think about everyday situations (Diário de Campo de Teolândia, BA; André, 2002, p.19).

Most teacher-trainees talked positively about the changes they adopted in planning and classroom practice:

Before, I used to make a daily class plan back to front: first I would deliver the class, then I would register it. . . Only when I came to Proformação, I learned how to make and use a class plan. I became more independent, more autonomous, more confident (Teacher Trainee, Teolândia, BA; André, 2002, p.12).

Proformação is very rich and helps a lot teachers in the classroom . . . Before, the teacher used to come to the classroom and dictate content, only dictate content, content without explanation. Nowadays, the teacher comes to the classroom, explains everything he is going to do, and goes about developing the class activities. It became easier for students to understand and learn the content (PC, Cacimba Velha, CE; André, 2002, p.12).

Results of classroom observation also points out Proformação's effects on classroom environment and class management strategies. These results indicate that the organization of the classroom to create an exciting learning environment is something all teacher-trainees are concerned about. Classrooms are decorated with posters and students' work, and teacher-trainees are more active in promoting group work and other activities, strengthening integration and collective work among students. "Besides using learning motivation materials, valuing students work and the place they live, the trainees organize the (classroom) space in a variety of ways to address the students' needs, in multi-grade classes” (André, 2002, p.17).

Results of these and other interview s with teacher-trainees reinforce our findings: "In all interviews, one can note the teacher awareness about his/ her changes and the concern (desire) of trying to transfer to the classroom what they have learned participating in Proformação "(André, 2002, p.12)

It must be noted, however, that changes in content knowledge appear to be less apparent. In two classrooms, the tutor observed that the teacher-trainees had difficulties with written language and math content. "The explanation may be that those teachers were educated by practicing. Since they are isolated in rural areas, they have some practices that require more time to change. Two years is too little to accomplish some more dramatic changes, such as content knowledge. This fact make us to stress the importance of continuing to foster this network of supervision and support of trainee teachers” (Andre, 2002, p. 32).

\section{Teacher Professional Development and Self-Esteem}

Survey results show that after participation in the program, 98 percent of teacher trainees reported that they perceive they are more valued by their school and communities, and 99.3 percent agreed that they had grown considerably within their profession. Tutors and teacher-trainees also indicated that the program contributed to an increase in self-esteem, in that they feel more valued professionally, which in turn has elevated their overall participation in their schools and 
classrooms. As such, teacher-trainees indicated they felt more respected in their school and local community.

Additionally, the results of case studies show that Proformação has created situations that foster teacher trainees' professional identity. Proformação appears to have given more consistency in their chosen career as educators. To many, participating in the program represented the realization of their dream of being a teacher (André, 2002).

With Proformação, I fulfilled a dream. One thing I [a teacher without certification] wanted most was not to be called "leiga teacher" . . I will finish Proformação and want to pursue pedagogy [a higher education course on education theories and teaching/learning methodologies]....

These results indicate that principal objective of Proformação - to raise teachers' professional value - has been achieved. "We can say that Proformação has contributed to the conquering of citizenship by these educators, who are now publicly acknowledged as qualified to exercise the profession. Besides legitimizing their rights, this certification gives them the feeling of being part of a group (André, 2002).

My life was transformed after Proformação. I learned much more, I learned to be more expansive, more patient, kinder with the kids. My life has really been transformed. Now I am truly a teacher. I can say I am truly a teacher after [completing] Proformação. (PC, Rio Branco, AC; André, 2002, p.13).

\section{Participation in the School and Community}

After completing the program, 99 percent of teacher trainees surveyed agreed that they had increased their participation in their schools. Analysis of case studies results showed that teacher trainees changed their attitude toward school meetings. They are more confident in participating and expressing their opinion about the school pedagogic plan and other school related activities. "Many of them began to feel they had rights after Proformação. Nowadays the trainees feel they have the right to express their opinions, to be on an equal footing as others in planning meetings or in a public activity” (Diario de Campo de Quixadá, CE: André, 2002, p. 13).

Nine-six percent of teacher trainees surveyed agreed in that it is easier to participate in their communities. High levels of participation were evident in the teacher-trainees' research projects, which addressed local issues, such as family violence; environmental problems; medical herbs found in their region, local culture, etc. These research projects involved not only the teachertrainees, but also their students, schools, and local communities. They also reported organizing cultural or scientific events with the participation of the local community and, in some cases, with local authorities.

\section{Program Operational Structure}

The majority of participants agreed that Proformação is a distance learning system that works well (98.3 percent of teachers trainees; 97 percent of tutors; and 100 percent of local managers). The fact that most tutors (95 percent), training teachers (100 percent), and local managers (100 percent) indicated that Proformação's monitoring system was "good," may indicate the main factor that helps explain the high-level of performance of teacher-trainees, many of which work 
in such disadvantaged situations (e.g., having few years of formal education). The majority of teacher-trainees (95.4 percent) reported they are "well guided to work with program's contents, and feel free to ask questions during the activities" (92 percent).

Although simple and apparently adequate in most cases, Proformação's infrastructure does vary among states. Survey results show that the place and conditions where face-to-face activities are conducted, are considered adequate (88.8 percent); as well as the location and conditions where biweekly meetings are held (87.6 percent). When asked these questions, participants in the State of Acre reported the lowest agreement rates: 81.6 percent and 80.7 percent, respectively; whereas the State of Permambuco reported the highest agreement rates: 94.6 percent and 93.1 percent.

These results indicate that more than 95 percent of participants surveyed in all States agreed that the teacher-trainees performed well. Eighty-four percent of teacher trainees surveyed reported that pedagogical support offered by telephone by the Training Agency is working well. This finding, however, was not evenly spread in that some States appeared to have more difficulties in this respect than others. For example, in Acre 7.6 percent and in Pernambuco 14 percent of teacher trainees did not agree that these services were functioning well.

In terms of tutor performance, the results of the evaluation were generally positive. The great majority of trainees (95 percent), in all States, agreed that their tutors fulfilled their specific roles in terms of following up and supervising their pedagogical practice, conducting biweekly meetings, clarifying doubts, providing guidance during individual studies, and encouraging teacher-trainees to study and apply new learning to their classroom practice.

Because the tutors' role is extremely important in Proformação pedagogical model, these results are extremely important. Indeed, when it is considered that teacher-trainees teach different grade levels, and yet the majority have not even completed basic education themselves, the role of the tutor in Proformação becomes truly central to the program's overall success. The presence and ongoing coaching and mentoring of individual tutors can and do influence teacher-trainees' motivation in the classroom in study, adoption and use of appropriate pedagogical methods (Placco, 2002, p.31).

\section{Partnership among Federal, State, and Municipal Governments}

Data gathered to analyze the partnerships with municipalities revealed that this is one area of apparent weakness, which deserves closer attention. Eighty-one percent of trainees agreed that they have received support from their municipality. However, when questioned on if they received support at the State level, the rates of agreement varied widely. The States of Acre and Goiás, reported the lowest agreement rates: 59.7 percent and 75.9 percent, respectively. In Ceará and Pernambuco, the highest agreement rates were reported: 87.4 percent and 92.3 percent, respectively.

When asked about the face-to-face sessions, the teacher-trainees' surveyed revealed weak points: lack of transportation (23 percent), and inadequate food (14.9 percent).

Of those surveyed, 89 percent of tutors reported that their salary was paid by their local municipality. Nevertheless, 44 percent of those same tutors surveyed indicated they did not have funding for transportation necessary to travel to the teacher-trainees' schools. Because these rates 
Bof Distance Learning for Teacher Training in Brazil

varied widely from State to States, such findings suggest uneven support for the program at the Municipal level.

One factor that explains, disparate levels of support, is that municipal elections were held at the end of 2000. These elections resulted in many changes taking place at the Municipal level. As such, the National Coordination Unit, as well as the State Management Team, and technical assessor developed a common strategy to offset the consequent threat of program discontinuity caused by changes in Municipal governments.

When comparing the fist and second rounds of data collection over the life of the program, however, findings revealed an improvement in the support of Municipalities. Tutors' salaries were usually paid on time, and needless duplication of work was eliminated (e.g., from municipal secretariats of education and from Proformação). Such improvements are likely due to the way Proformação works: on one hand, efforts are being made to integrate the administrative activities of Municipal, State, and Federal governments; on the other hand, implementation agents, such as the National Coordination Unit and Training Agencies, have also made tremendous efforts to resolve problems during program implementation. In sum, the effort and personal commitment of all parties involved to talk, share information, and coordinate activities, have been important ingredients in the program's success (André, 2002).

\section{Program Quality}

Proformação is viewed as a high quality teacher training-program by most participants: teachertrainees (99 percent), tutors (98 percent) and local managers (100 percent). Those surveyed viewed the program as not being overly theoretical and contributing to increased quality of classroom teaching. It was considered by 88.8 percent of training-teachers and tutors surveyed, as equal to traditional (face-to-face) teacher-training programs. Only 4.3 percent disagreed with this view, and seven percent offered null responses. Ninety-eight percent of respondents agreed that teacher-trainees received quality certification training through Proformação.

\section{Lessons Learned}

The novelty, size, and decentralized operational structure of Proformação imposed some challenges on the implementation team. When difficulties arose, corrective actions had to be taken. As such, several important lessons were learned, all of which should be taken into consideration when undertaking similar programs. Some of these "lessons learned" are presented below:

Having a detailed implementation plan in advance is crucial to a successful implementation. Moreover, all participants must have adequate training from the outset, allowing them to participate satisfactorily in the program. No implementation can be successful without providing clear information to all program participants about what they are supposed to do and how they can do it. After evaluating the results of the pilot study, the need for careful preparation and training of State Management Teams, technical assessors, Training Agency teams, and the tutors, was evident. Thus, a training program was established and specific implementation support guides were developed to guarantee that information could be readily available to all implementation agents. As reported by participants later, having well-defined training and materials was essential to successful implementation. Additionally, ongoing support was available to all participants, so that problems could be resolved as needed, at any time. 
Having enough time to conduct both planning and training can prevent subsequent difficulties during implementation. Proformação, however, was implemented in an extremely tight timeframe. The experience gained, however, reveals that it takes time to plan all the details of an implementation strategy, and it takes time to prepare those who are charged with implementing it. In sum, these aspects must be considered fully, to avoid difficulties during the implementation process.

Having instruction materials ready prior to implementation is strongly recommended. Revision of Proformação instructional materials, for instance, was carried out during the implementation process. This situation resulted in serious delays, especially during the beginning-phase of the program. The suggested solution is to develop a contingency plan, wherein teacher-trainees are engaged in face-face sessions with their tutors, until the arrival of (revised) print-based materials arrive. This experience showed that in distance learning courses, it is crucial to guarantee that materials are ready prior to beginning the course. However, if there is any doubt about whether material will be available on time, the contingency plan described above is strongly recommended.

The establishment of an effective partnership among institutions and governments is likewise recommended. It is essential, however, to have a well-defined legal arrangement to ensure each partner knows their respective areas of responsibility and parameters for fulfillment of such legal responsibilities. Moreover, it is most advisable to avoid, if possible, electoral periods and changes in local governments. A main problem in the implementation of Proformação, for example, arose when some newly elected municipal governments did not abide by the agreement signed by the previous government. To deal with this problem, the Local Management Team and technical assessors visited several municipalities to explain their position. Unfortunately, in some cases, the National Coordination Unit had no choice but to engage Brazil's legal system to enforce the agreement. Our experience was that undesired situation took place after the municipal elections were held, or in the middle of program implementation. In sum, several changes occurred in several municipal administrations, which in turn created problems for the continuity of the program. In all cases, having a legal instrument to support the agreement was essential, allowing even for judicial actions.

An integrated information system is crucial for the management, monitoring, and evaluation of a program such as Proformação, but like other elements of the program, it also takes time and effort to make it functional to support the program's specific information and communication needs. Proformação developed an information system to collect management data and monitor varying levels of program results and activities. Our experience was that it took more time to implement a functional system at the local level than we had originally anticipated, particularly if participants are not computer literate. Training strategies must therefore be well thought-out in advance to help individual Training Agencies resolve computer literacy problems as they arise.

It is possible to organize an effective decentralized distance learning system. Proformação represents a different way of organizing a system to deliver education at a distance. By establishing a highly structured system, engaging local partners by investing in their training and continuous motivation, and having a good support and monitoring system, it shows that it is possible to provide good training opportunities to those who live isolated or in rural areas.

Monitoring and evaluation mechanisms at all levels are fundamental for quality control. The Proformação experience shows that the success of the program is largely due to the existence of 
monitoring and evaluation mechanisms and instruments that allowed implementation agents to identify problems and propose solutions in a flexible and fluid manner.

Efficient communication channels are also important to program Implementation. In distance learning programs such as Proformação, with so many partners and participants involved, the establishment of an efficient communication system is essential to success. Such as system is not only needed to send and receive relevant information, it also provides the mechanism through which all involved can be proactively motivated - especially those who need to feel they are not alone in the process.

\section{References}

André, M. (2002). Relatório de Avaliação Externa do Proformação: Estudo de Casos. Brasília: SEED - MEC.

Gatti, B. (2002). Relatório de Avaliação Externa do Proformação: Pesquisa de Opinião. Brasília: SEED - MEC.

Guia Geral do Proformação (2000). Brasília: MEC.FUNDESCOLA.

Manual de Operacionalização do Proformação (2000). Brasília: MEC.FUNDESCOLA.

Moore, M (2001). Brazil's Proformação. 20th World Conference on Open Learning and Distance Education, Düsseldorf, Germany.

Placco, V. (2002). Relatório de Avaliação Externa do Proformação: EntrevisTraining Agencies. Brasília: SEED - MEC.

Relatório (2000). Proformação. SEED - Ministério da Educação.

\section{Endnotes}

1. External Evaluation team: Prof. Dra. Bernardete Gatti (Carlos Chagas Foundation/Catholic University (PUC) -SP); Prof. Dra. Vera Placco (Catholic University (PUC) -SP), and Prof. Dra. Marly André (University of São Paulo/ Catholic University (PUC) -SP).

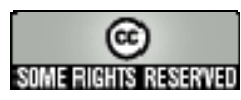

